\title{
O Principio da Lei mais Favorável no DIP
}

\author{
Haroldo Valladão \\ Catedrático de Direito Internacional Privado das \\ Universidades Federal e Católica do Rio de Janeiro.
}

\begin{abstract}
SUMÁRIO: I. O tema: a lei mais favorável no DIPr. II. Tratamento doutrinário e legislativo (Proj. Bras. de DIPr.). III. Origem do principio, Códs. Prússia, 1794 e Austria, 1811. IV Enfoque na América Latina: TeIXeIra DE Freitas, Brasil, 1860 e Cód. Civ. Argentino, 1869 -- Atos e capacidade. V. Repercussão em vários países. VI. Nas Convenções Internacionais. VII. $O$ direito brasileiro - O Anteproj. Br. Lei Geral de Aplicação das Normas Jurídicas. VIII. A razão do princípio. IX. O principio da lei mais favorável no Direito de Família. X. Na Filiação e nos Alimentos. XI. Na Tutela e Curatela. XII. O princípio da lei mais favorável no direito de sucessões. XIII. $O$ alteamento do princípio na Constituição Federal Brasileira de 1934 - Sua adoção no Proj. Brasileiro, art. 64 e \& unico. XIV No Direito de Sucessões comparado, em especial da América Latina. XV Conclusão.
\end{abstract}

I. Escolhi para este trabalho, assunto pouco estudado no Direito Internacional Privado: o princípio da lei mais favorável nos Conflitos de leis.

Muito antigo e restrito, na matéria, tomou vulto e amplitude ultimamente.

É um elemento de conexão original, pois parte de uma comparação substancial entre a lei do país onde se levantar a questão, habitualmente a lei do foro, a lei nacional, e a lei ou leis estrangeiras que a impregnaram.

E concluiu-se pela aplicação da lei que for mais favorável, seja à validade do ato, ou ao menor ou incapaz, ao filho, ao pupilo, ao alimentando, ao devedor, ao herdeiro legítimo...

II. Defendi e preguei o princípio em minha obra, DIPr., vol. I5, 1980, na Introdução: Por um DIP progressista, vol. II $^{2}$, 1977, Capítulos XLII, n. 8 ; XLIII, n. 7 ; L, n. 16; LII, ns. 12 e 13 ; LVI, n. 6 ; LX, n. 11; vol. III, 1978, Cap. LXII, n. 12 . .

Dei-lhe grande aplicação no Projeto, oficial, que organizei para o Brasil, da Lei Geral de Aplicação das Normas Jurídicas, Capítulo III, Disposições de DIPr. 
E o fiz com muitas regras, em particular a propósito da capacidade de agir, arts. $25 \S 1 .^{\circ}$, forma extrínseca dos atos, $29, \S 2 .^{\circ}$, prescrição extintiva, 31, parágrafo único, casamento, 34 , c/ $\S \S 1 .^{\circ}$ e $2 .^{\circ}$; filiação, 42 , tutela e curatela, 41 ; alimentos, 42; obrigações, $50 \S 4 .^{\circ}$; cambial, arts. 55 e 56 ; sucessões, art. 65 , parágrafo único.

III. O princípio, também chamado do favor negotii, tem origem mui remota. Encontrei-o em GrotiUs, L. II, Cap. XI, n. V, 2, e, ainda, no Cód. da Prússia (1794), art. 35 “ pela lei que for mais favorável à validade dos contratos" E o Código Civil da Áustria (1811) consagrou-o, declarando que "um negócio realizado por um estrangeiro neste Estado se julga seja por éste Código, seja pela lei nacional do estriangeiro, por uma ou outra, segundo mais favoreça a validade do ato".

SAVIGNY elogiou-o propondo sua universalização (§ 365) e Bluntschli incluiu-o no Código Civ. de Zurique, 1854 $\left(\operatorname{art} . .^{\circ}\right)$.

IV. Na América Latina, o insigne jurista brasileiro, Augusto TeIXeIRA DE FREITAS, deu ao princípio alto e definitivo valor, com regra genérica na matéria, art. $5 .^{\circ}, \S 4 .^{\circ}$ (quando as leis deste Código, em colisão com as estrangeiras, forem mais favoráveis à validade dos atos) ao lado das restrições de ordem pública, $\S \S 1 .^{\circ}, 2 .^{\circ}$ e $3 .^{\circ}$. Leia-se da sua Justificação: “ bom expediente tomado pelo Código da Prússia, e bem se vê que é geral, ou a validade do ato aproveite a nacional ou estrangeiro. Nos livros franceses, porém, essa mesma idéia aparece, mas como um favor aos nacionais, conseqüência infalível de sua viciosa legislação, ainda impregnada do jus quiritium, jus proprium civitatis, do primitivo Direito Romano" (nota ao texto)".

Seguiu-o, na República Argentina, o notável jurista, VELEZ SARSFIELD, que adotou os textos de FREITAS, integralmente (vd. Material de Classe, pág. 279), Cód. Civ. Argentino, art. 14 (sempre em vigor).

V. Esse grandioso enfoque de Freitas e do Cód. Civ. Argentino veio a ser seguido em vários textos dos principais países.

Assim foi adotado pela Lei Int. Cód. alemão, art. $7 .^{\circ}$, alínea 3, copiado nas leis japonesas, art. $3 .^{\circ}$, chinesa, art. $5 .^{\circ}$, no Cód. Suíço, art. 59 c/ 7 b, e nas D.G. Cód. italiano de 1929/42, art. 17, alínea 2 (incluídas nas exceções as doações) ; entrando na Lei do Sião, art. 10, no Cód. da Grécia, art. 9. ${ }^{\circ}$ (só excepcionando sucessões e imóveis sitos no estrangeiro), no Projeto húngaro, art. 47 (só para os atos de coméricio), no recente Cód. 
Civ. port., 28/III, e na Lei da Polônia, art. 10 (excluídos apenas direitos de família e sucessórios) enquanto a lei anterior, de 1926, só reconhece a capacidade se a segurança de um comércio honesto o exige. O Cód. Civ. da Rússia Soviética, RSFSR, art. 562 , adota o princípio da validade da forma, também segundo a lex fori. Igualmente as Leis da Coréia do Sul, art. $10 \S 2 .^{\circ}$, e da Albânia, art. 21. Na França, um critério subjetivo, ou do "interêt national", validando um contrato ali feito se um dos contratantes é francês (célebre affaire Lisardi, de 16/1/1861, de um mexicano menor de 25 anos), ou presumindo o desconhecimento pelo nacional da lei de incapacidade estrangeir'a (BATIFFoL, n. 417) evoluiu no Projeto francês para ter aplicação bilateral, art. 29. O Proj. argentino, 1954, art. 6. ${ }^{\circ}$, após determinar que a capacidade de exercício se rege pela lei do domicílio, faz ressalva amplíssima, alínea 3, estabelecendo "que o incapaz pela lei do domicílio será considerado capaz, se o for pelas leis deste Código", na tradição de FrEITAS.

VI. O Código Bustamante não formulou a ressalva, art. 27, mas acatou-a em parte, pois mandou reger a capacidade pela lei pessoal, salvo as restrições deste Código ou do direito local.

Está, porém, a ressalva consagrada nas Convenções de Genebra, de 1930, sobre Conflitos de Lei em Matéria de Cambial e de Cheque, art. 2. ${ }^{\circ}$, alínea 2 , ratificadas pelo Brasil, e promulgadas pelo Decr. 57.663, de 24-1-1966.

VII. O direito brasileiro já antevia o princípio no Reg. 737 , de 1850 , art. $3 .^{\circ}, \S 1 .^{\circ}$, alínea 2 , e veio depois confirmá-lo no art. 42 parágrafo único, da Lei Cambial, para a capacidade.

O Anteprojeto da Lei Geral de Aplicação das Normas Jurídicas acolheu o princípio nos arts. $25 \S 11^{\circ}$, quanto à incapacidade de agir, $29 \S 2 .^{\circ}$, forma extrínsecta dos atos, 34 , $1 .^{\circ}$, forma do casamento (favor matrimonii) e $50 \S 4 .^{\circ}$ fine, sobre lugar do contrato, 55 e 56, capacidade e forma da cambial.

VIII. A razão do princípio da lei mais favorável, quanto à forma extrínseca, apoiou-se modernamente na idéia de que a forma é um requisito precário, secundário. Não deve nunca ser fundamental, inarredável. E um ato jurídico deve ser sempre amparado, só podendo ser nulo por motivos de alta gravidade.

IX. O princípio da lei mais favorável teve grande e mui justa repercussão no direito de família.

Em nossa obra, DIP II, 1977, abrimos capítulo autônomo, n. ${ }^{\circ}$ XLIV, sobre Direitos de Família, em geral, e estudamos, ali, em particular o conflito das leis pessoais dos cônjuges. Após 
largo exame da doutrina, da legislação e da jurisprudência, pudemos concluir como se segue.

A nova Lei de Introdução ao Código Civil, consagrando o princípio do domicílio para os direitos de família, estabeleceu a lei do primeiro domicílio conjugal quando os nubentes têm domicílios diferentes, prescrevendo que em caso de abandono a mulher e os filhos terão direitos a um domicílio próprio. A eventualidade da diversidade ainda não foi examinada pela jurisprudência, mas a mulher a quem a lei concedeu um domicílio próprio terá o direito de invocar a lei do seu domicílio, sobretudo se se trata de um antigo domicílio comum e se ela é brasileira.

O Projeto da Lei Geral adotou vários critérios: para efeitos pessoais, a lei da residência habitual comum, salvo a lei brasileira no Brasil, para o cônjuge que aí reside, art. 35 ; para o regime de bens, a lei do primeiro domicílio conjugal e, se este não se constituiu, a lei do lugar da realização do casamento, art. 36, a separação (desquite) pela lei brasileira, no Brasil, se um dos cônjuges for brasileiro ou aqui tiver residência. Para a filiação em todas as suas formas, para a tutela e a curatela e no direito a alimentos, a lei mais favorável ao filho ou ao incapaz ou ao alimentando, dentre as leis da nacionalidade, do domicílio, ou da residência, do pai, da mãe, do tutor, do curador, do alimentante, do mesmo filho, do incapaz ou do alimentando, arts. 40, 41 e 42, mantidos todos na Revisão de 1970.

Estamos no penúltimo (o último está sempre por vir) estádio da evolução do problema. Superada a lei nacional ou domiciliar do marido, do pai, do tutor, do curador, do alimentante, caminhou-se para a do domicílio ou da residência habitual e comum, para a lex fori coincidente com a da nacionalidade, domicílio ou residência duma das partes, e, afinal, pela lei mais favorável à pessoa que visou proteger (DIP cit., II, p. $49 / 50$ ).

$\mathrm{X}$. Vejamos em particular a filiação e os alimentos.

Eis o texto do Projeto da Lei Geral para a filiação: "Art. 40 - A filiação em todas as suas formas e os direitos e deveres dela resultantes se regerão segundo a lei mais favorável ao filho dentre as leis da nacionalidade, do domicílio ou da residência do pai, da mãe ou do mesmo filho"

Foi a consagração de uma luta desenvolvida no século atual, no mundo e no Brasil (onde demos todos nossos esforços), não só legislativa mas, também, doutrinária e, especialmente, jurisprudencial, contra a tradicional aplicação, sempre, da lei dos 
países (vp. H. Valladão, DIP, II, Capit. LI, n. 5, 6 e 7 ; vd. também a Exposição de Motivos do Projeto, ps. 79/80).

Note-se ali a interessante evolução jurisprudencial, de uma simples aplicação da lei brasileira do filho, para aplicação da lei estrangeira do mesmo filho, se esta lhe era mais favorável.

Ficamos felizes por ver, afinal, a nossa campanha consagrada na conservadora França, anos após, na sua Lei 72, 3 de janeiro de 1972, sobre Filiation, Aliments, Conflits de Lois.

Admitiu, amplamente, a lei pessoal do filho, art. 311, 14 e 15, inclusive se residente em França, a lei francesa da posse de estado, mesmo se pudesse depender de uma lei estrangeira por outros elementos da filiação.

Afinal, em os novos arts. 311-16 e 17, admite-se a legitimação, seja pela lei do casamento, seja pela lei pessoal de um dos cônjuges, seja pela lei pessoal do menor, e o reconhecimento voluntário da paternidade ou maternidade se conforme com a lei pessoal, seja do respectivo autor, seja do menor.

Em matéria conexa, alimentos, a legislação francesa também evoluiu, plenamente, no sentido do Projeto brasileiro.

Eis o texto do Projeto da nossa Lei Geral: "Art. 42 - O direito a alimentos entre parentes se rege segundo a lei mais favorável ao alimentando dentre as leis da nacionalidade, do domicílio ou da residência do alimentante ou do mesmo alimentando".

E a redação da lei francesa, citada, $72-3$ janeiro de 1972 , 311-18: "L'action à fins de subsides est régie, au choix de l'enfant, soit par la loi de sa résidence habituelle, soit par la loi de la résidence habituelle du débiteur" (vd. H. VAlladão, DIP, vol. II, Cap. LI).

XI. Acerca da Tutela e da Curatela, o Projeto brasileiro da Lei Geral, art. 41, dispôs na orientação que vimos pregando: "A tutela e a curatela gerais e especiais se regem segundo a lei mais favorável ao incapaz dentre as leis da nacionalidade, do domicílio ou da residência do tutor, do curador ou do incapaz".

Representa o último estágio do direito, da legislação e da jurisprudência, brasileiros, na matéria (vd. H. VALLAD ̃̃o, DIP, II, 1977, Cap. LII).

XII. Vejamos, agora, o princípio da lei mais favorável no DIP brasileiro das Sucessões. 
É um princípio tradicional do nosso direito que vem do século XIX em Convenções Internacionais e atinge o ponto máximo desde 1934, integrando texto constitucional.

Nas Convenções Consulares do Império, vindas até os começos da República, com Portugal (Decr. 6.236 de 1876, artigo 28), com a Itália e a França (Decrs. 6.582 de 1877 e 7.110 de 1878, artigo 29), com a Espanha (Decr. 7.059 de 1878, artigo 35), com a Suíça (7.303 de 1879, artigo 23) e com a. Alemanha (Decr. 8.616 de 1882, artigo 35), adotou-se para reger a sucessão o princípio da lei do país a que pertencer o falecido, aplicando-se, assim, o princípio da nacionalidade, salvo na Convenção com a Espanha na qual só o admitiu para os bens móveis.

Mas previram-se os conflitos sobre leis pessoais, concorrendo numa sucessão herdeiros nacionais e estrangeiros.

E se estabeleceu um princípio original para a solução dos conflitos das leis pessoais, entre herdeiros brasileiros e estrangeiros, consistente na preferência que se dava ao nacional que concorresse em seu país com herdeiros estrangeiros, de optar pela lei de sua pátria.

Eis o texto da convenção com a Itália: "Quando, porém, acontecer que algum súdito de uma das altas partes contratantes concorra em seu país com herdeiros estrangeiros, terá ele o direito de preferir que o seu quinhão hereditário seja regulado nos termos da lei de sua pátria"

Foi a consagração do princípio da lei mais favorável, pois dava-se ao herdeiro, em seu país, o direito de escolher a lei de sua pátria.

Esse princípio constou do Projeto Felício, art. 20, parágrafo único, e foi consolidado por CARLOS DE CARVALHo, art. 31, parágrafo único.

Mas na antiga Introdução do Código Civil, 1917, art. 14, fine, o preceito mandando aplicar sempre a lei brasileira, restringia a opção tradicional do herdeiro brasileiro ao declarar que se o falecido era casado com brasileira, ou tiver deixado filhos brasileiros, ficarão eles sujeitos à lei brasileira, e, na Lei de Introdução, o $\S 1 .^{\circ}$ alterava o texto constitucional ( $\mathrm{H}$. VALLADÃo, in RTSP 203/3 e ss., e BSBDI, 13-14-34 e ss.) Eram textos, inconveniente um e inconstitucional o outro.

XIII. Afinal a Constituição Federal de 1934 elevou o princípio à categoria jurídica máxima, assim o enunciando: 
“Art. 134 - A vocação para suceder em bens de estrangeiros existentes no Brasil será regulada pela lei nacional em benefício do cônjuge brasileiro e dos seus filhos, sempre que não lhes seja mais favorável o estatuto do de cujus".

O Anteproj. L. Geral manteve-o na forma da Constituição de 1946 e 1967: "Art. 64 - A vocação para suceder em bens de estrangeiro existentes no Brasil será regulada pela lei brasileira e em benefício do cônjuge ou de filhos brasileiros, sempre que lhes não seja mais favorável a lei nacional do de cujus" (art. 165, C.F.).

E o parágrafo único estendeu o princípio, por força de compreensão, com justiça, à sucessão do brasileiro domicitiado no estrangeiro (art. 63), e nesse sentido opinaram EsPínola e FILHO (L.I., 111-137).

Realmente, veio completar a finalidade do texto constitucional, aplicando o princípio também no concurso com a lei estrangeira do domicílio. O Supremo Tribunal Federal consagrou tal modo de ver, aceitando esse parágrafo único no voto do eminente Min. VILlas-BoAs, encontrado in Rec. Extr. 59.871 do Rio Grande do Sul, RTSTF, 38/168, ali vencido mas, afinal, acolhido unanimemente pelo Tribunal Pleno, em embargos, Relator o eminente Min. Eloy José DA RochA, ac. de 26-V-1971, RTSTF, 59/270. Eis a ementa: "Vocação para suceder, vigente a Constituição de 1946, em bens situados no Brasil, pertencentes a brasileiro domiciliado no estrangeiro. Incidência da lei sucessória brasileira, em benefício de filha adotiva brasileira, igualmente domiciliada em outro país. Aplicação, por força de compreensão, do art. 165 daquela Constituição. Embargos de divergência conhecidos e recebidos".

A Emenda Constitucional n. ${ }^{\circ}$ 1, art. 153, $\S 33$, substituindo no final do texto "lei nacional do de cujus" por "lei pessoal do de cujus", veio dar, ainda, maior dimensão ao princípio, bastando que a lei do falecido, ou de sua nacionalidade ou de seu domicílio, ou mesmo de sua residência ou religião, seja mais favorável ao cônjuge ou aos filhos brasileiros.

XIV. O princípio existe em grande número de países, seguidores ou da lei nacional, Alemanha, art. 25, Honduras, 978, Holanda, Lei de 7-4-1869; ou da lei do domicílio, Chile, art. 998, Salvador, 995, Equador 1.056, Argentina, 3.470, Colômbia 1.034, Nicarágua, 1.024, Peru, Cód. de 1936, art. 659, e no recente Projeto da Venezuela (1963), art. 35 ; ou da lex rei sitae para os imóveis e da lex domicilii para os móveis, França, Lei 14-7-1819, 
art. 2. ${ }^{\circ}$, Bélgica Lei 27-4-1865, art. $4 .^{\circ}$, Áustria, Lei de 9-8-1854, Liechtenstein, Lei de 4-12-1911, art. 3. , Projetos franceses, 1950, art. 55, e 1967, 2309, até no regime da lex rei sitae para todos os bens, do Projeto argentino de 1954, art. 18, fine...

XV. O princípio acima exposto e defendido, corresponde ao novo DIP que vimos pregando, a um Direito Internacional Privado progressista (vd. H. VALLADÃo, DIP, T. 1, 5. ${ }^{\circ}$ ed., 1980, páginas iniciais, Por um DIP Progressista).

\section{Projeto Brasileiro de Lei Geral de Aplicação das Normas Jurídicas}

Incapacidade de fato (Art. $25, \S 1^{\circ}$ ) - Não será nulo o ato de direito das obrigações realizado no Brasil, se o agente for capaz pela lei brasileira.

Forma extrínseca dos atos (Art. 29, § 2. ${ }^{\circ}$ ) - Não serão nulos no Brasil, por defeito de forma extrínseca, atos que seriam válidos segundo a lei brasileira.

Prescrição extintiva (Art. 31, parágrafo único) - Será, todavia, decretada no Brasil se atingir o prazo da prescrição ordinária na lei brasileira.

Casamento (Art. 34, § 1. ${ }^{\circ}$ ) - Não será decretada, no Brasil, a inexistência, a nulidade ou anulação de casamento que for válido segundo a lei brasileira.

Filiação (Art. 40) - A filiação em todas as suas formas e os direitos e deveres dela resultantes se regerão segundo a lei mais favorável ao filho dentre as leis da nacionalidade, do domicílio ou da residência do pai, da mãe ou do mesmo filho.

Tutela e Curatela (Art. 41) - A tutela e a curatela gerais e especiais se regem segundo a lei mais favorável ao incapaz dentre as leis da nacionalidade, do domicílio ou da residência do tutor, do curador ou do incapaz.

Alimentos (Art. 42) - 0 direito a alimentos entre parentes se rege segundo a lei mais favorável ao alimentando dentre as leis da nacionalidade, do domicílio ou da residência do alimentante ou do mesmo alimentando.

Obrigações (Art. 50, § $4 .^{\circ}$ ) - Ocorrendo conflitos de leis sobre a conceituação do lugar do contrato, aplica-se a lei brasileira se esta o localizar no Brasil; se o conflito for entre leis estrangeiras, aplicam-se, subsidiariamente, as leis da residência habitual, do domicílio ou da nacionalidade dos decla- 
rantes ou comum dos contratantes, e, na falta, as do lugar da execução; permanecendo a dúvida, regem as leis mais favoráveis à plenitude da intenção dos interessados.

Cambial - Capacidade e forma (Arts. 55 e 56) - Iguais aos arts. $25, \S 1 .^{\circ}$ e $29, \S 2 .^{\circ}$.

Sucessões (Art. 64) - Igual ao art. 153, § 33 da Constituição Federal. Art. 64, parágrafo único. A vocação para suceder em bens móveis, existentes no Brasil, de brasileiro domiciliado no estrangeiro, será regulada pela lei brasileira sempre que lhes não seja mais favorável a lei estrangeira (Constituição Federal, art. 165).

Testamento - capacidade (Art. 65, parágrafo único) Não será inválido no Brasil, por defeito de capacidade, o testamento válido segundo a lei brasileira se esta reger a sucessão. 